\title{
A causa dos divertimentos
}

\author{
Rui Pina Coelho
}

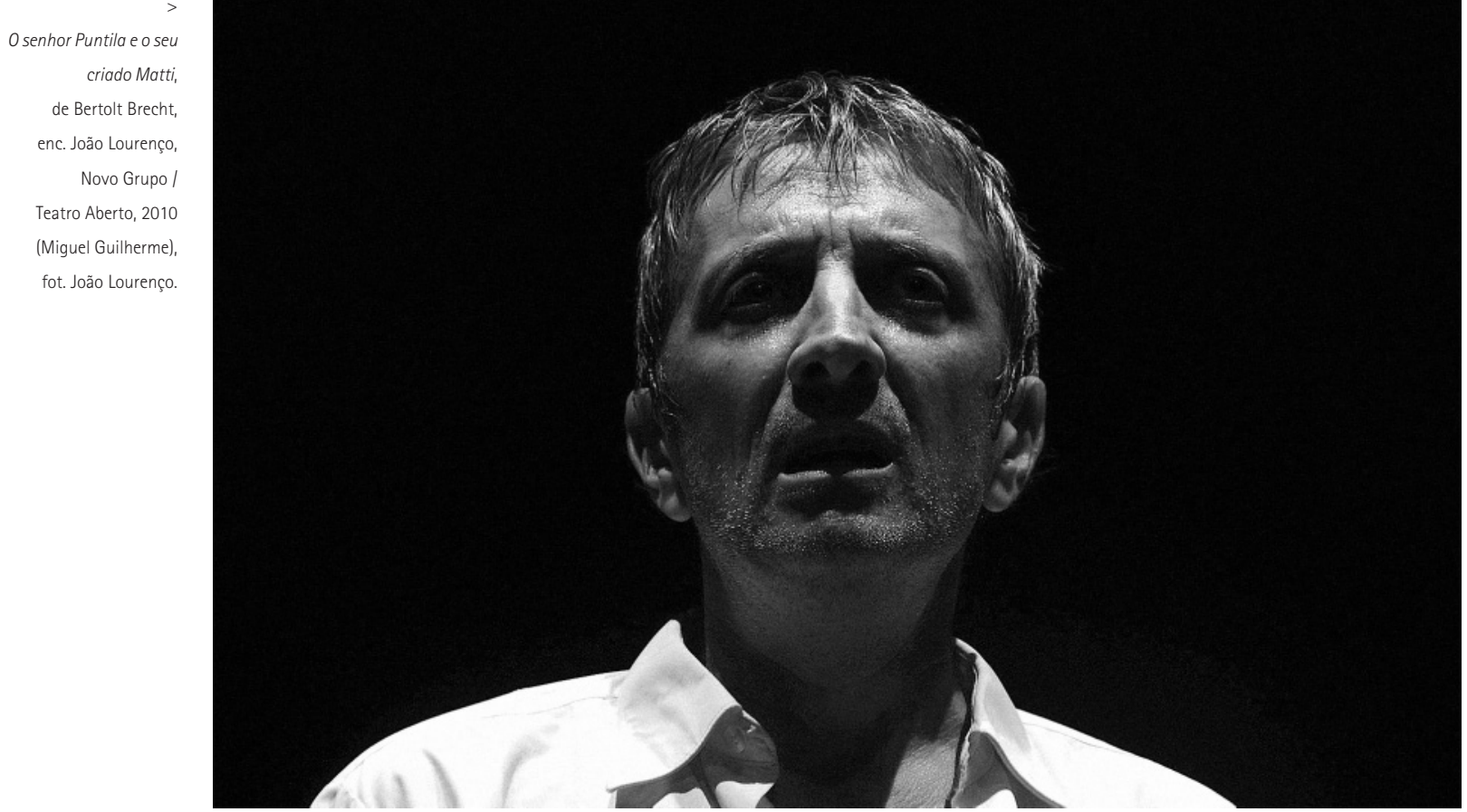

Em 1975, quando Mário Barradas e José Peixoto davam corpo ao Proprietário Puntila e seu criado Matti, publicavase no programa desse espectáculo do Centro Cultural de Évora alguns textos enviados pelo Berliner Ensemble respeitantes à encenação deste texto de Bertolt Brecht, em Berlim, nesse mesmo ano. Esses materiais chegavam ao Alentejo com os desejos expressos de "um bom êxito e um resultado eficaz do ponto de vista revolucionário". Os tempos, hoje, são inegavelmente outros e nos trinta e seis anos, que entretanto passaram, Portugal mudou, o teatro mudou e 0 papel que um texto como 0 senhor Puntila e o seu criado Matti pode desempenhar mudou, forçosamente, também. Um texto que, tal como escrevia Carlos Porto, no Diário de Lisboa, de 22 de Dezembro de 1975, "é uma peça de trabalhadores e de patrões".

Falar da eficácia de um espectáculo "do ponto de vista revolucionário" parece - infelizmente - coisa do passado e resquício anacrónico de um outro tempo. Contudo, as tensões entre trabalhadores e patrões voltaram a ganhar destaque de primeira página e, em rigor, a cerimónia de entrega dos Prémios da Crítica - prevista inicialmente para 12 de Março - foi adiada uma semana porque nesse dia, nas ruas de Lisboa, se manifestavam cerca de 300.000 mil pessoas, denunciando as situações de precariedade laboral em que grande parte dos trabalhadores portugueses se encontram
Ainda assim, o teatro parece ter abdicado daquilo que "assombrou grande parte das experiências teatrais do século XX": o "sonho de um teatro político", tal como o designa Joe Kelleher em Theatre \& Politics. Para este autor, o teatro tem uma qualidade política intrinseca porque reúne um colectivo vivo de pessoas, num determinado espaço e num determinado momento. Nesse sentido, Kelleher argumenta que o teatro tem a capacidade de enunciar e apresentar o mundo como ele é e, consequentemente, de propor alternativas. Com efeito, afirma que:

\footnotetext{
[0] teatro pode falar 'para' nós, e 'de' nós, já para não falar do mundo dos outros. 0 teatro representa-nos, tanto no sentido de proporciona imagens de nós próprios, como no sentido de nos representar ou defender, como um delegado, um substituto ou - até mesmo - como um representante politico. (Kelleher 2009: 10, trad. minha).
}

Se alguns vêem nisto a ameaça de um teatro doutrinário, propagandístico ou moralista, é o próprio Brecht que ajuda a dissipar as suspeitas. Assim, n' 0 pequeno organon para o teatro, escreve:

[0] teatro [...] tem estado, desde sempre, empenhado em divertir. E é este empenho, precisamente, que Ihe confere [...] uma dignidade especifica, basta-Ihe o prazer, prazer que terá que ser, evidentemente 


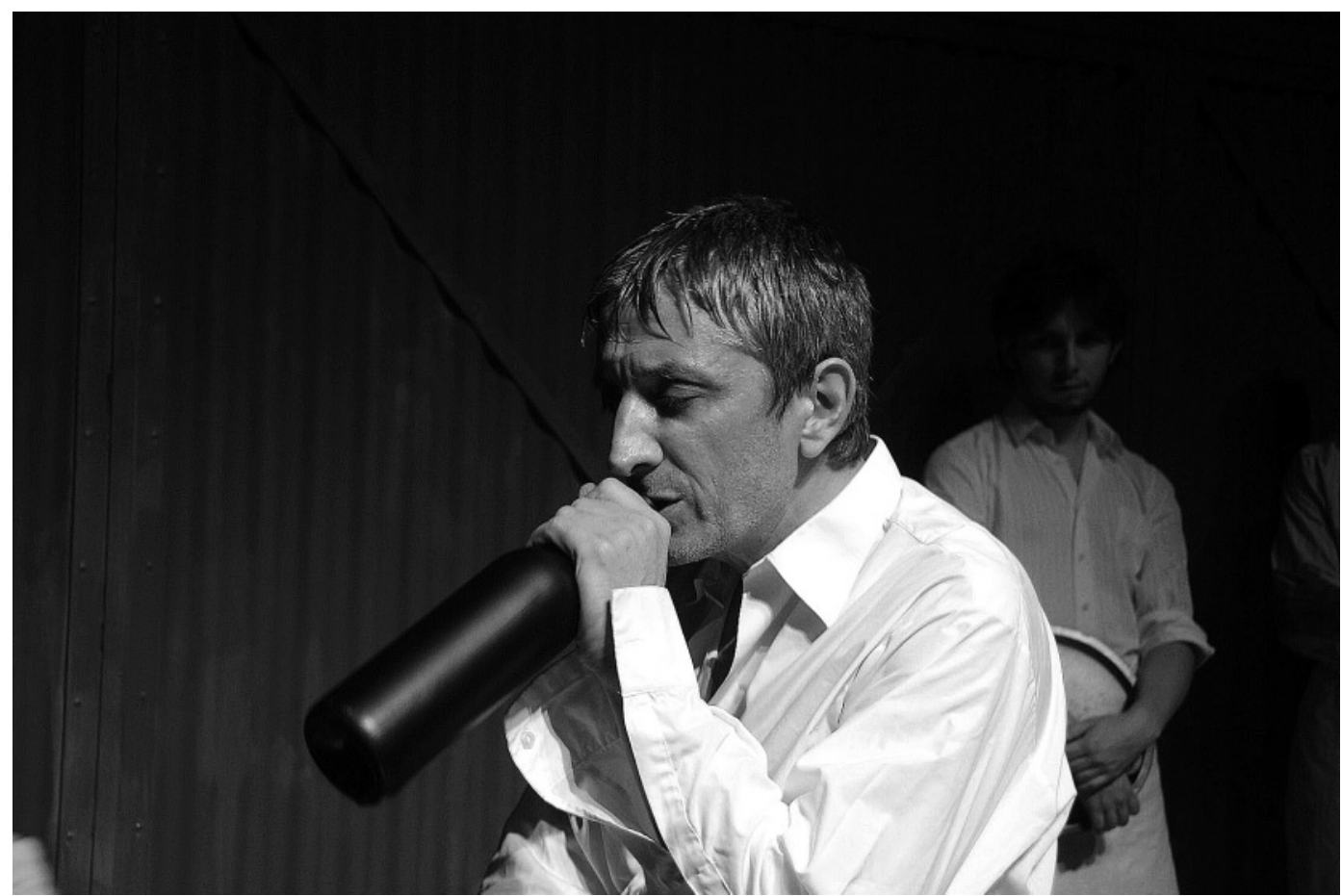

Osenhor Puntila e o seu

criado Matti,

de Bertolt Brecht, enc. João Lourenço, Novo Grupo / Teatro Aberto, 2010 (Miguel Guilherme e Carlos Malvarez), fot. João Lourenço.

absoluto. Tornando-o um mercado abastecedor de moral, não o faremos ascender a um plano superior; muito pelo contrário, o teatro tem justamente de se precaver nesse caso, não vá degradar-se, o que certamente sucederá se não transformar o elemento moral em algo aprazivel, ou, melhor, susceptivel de causar prazer aos sentidos.

(Brecht 1964: 162)

E é essa a extraordinária habilidade do espectáculo encenado por João Lourenço: simultaneamente divertir e manter a áspera lição de Brecht com a pertinência necessária - um espectáculo de trabalhadores e patrões para o mundo do século XXI, o da precariedade, dos recibos verdes, dos estágios não remunerados, enfim, daquilo a que nos jornais agora chamam a geração parva ou à rasca.

O senhor Puntilla e o seu criado Matti, peça composta entre textos como As espingardas da senhora Carrar, Terror e miséria do Terceiro Reich, A boa pessoa de Sé-Chuão ou Mãe Coragem e os seus filhos, textos com uma tensão política potencialmente maior, é uma deliciosa comédia popular onde se narra a história do senhor Puntila, um patrão que revela qualidades humanas extraordinárias, um elevado sentido de justiça e um desprezo pela hipocrisia quando está bêbado, e que, uma vez sóbrio, cai no estigma do patrão tirano; sempre acompanhado pelo seu fiel criado Matti, um homem culto, intelectualmente superior e em plena aprendizagem revolucionária. 0 espectáculo apresentado no Teatro Aberto unia, assim, a poderosa lição brechtiana a uma felicidade de representação que entusiasmava, pela diversão, o público.

E o Miguel Guilherme? "A análise do espectáculo deveria começar pela descrição do actor, pois este está no centro da representação e tende a chamar o resto da representação para si", escreve Patrice Pavis no seu já clássico A análise dos espectáculos (Pavis 2003: 49). Não sei se será sempre assim, mas neste caso em concreto, deveríamos começar pelo actor Miguel Guilherme.

Mas é claro que não o podemos fazer sem referir também a impecável contra-cena de Sérgio Praia, que compõe um Matti, ao mesmo tempo animal selvagem e criatura doméstica, vibrante de corpo e raciocínio, e que garantia, com Puntila, o equilibrio necessário ao espectáculo, jogando ambos como se de uma parelha cómica se tratasse. Nem nos podemos esquecer da melíflua Sofia Portugal, a filha do patrão, a face visivel da aprendizagem épica. Nem, em rigor, podemos deixar de referir todos os outros actores e músicos - António Pedro Lima, Cátia Ribeiro, Carlos

Malvarez, Carlos Pisco, Cristóvão Campos, Francisco Pestana, João Fernandez, Mafalda Lencastre, Mafalda Luís de Castro, Marta Dias, Miguel Tapadas, Patrícia André, Rui Morrison, Sara Cipriano e Vasco Sousa - que compunham 


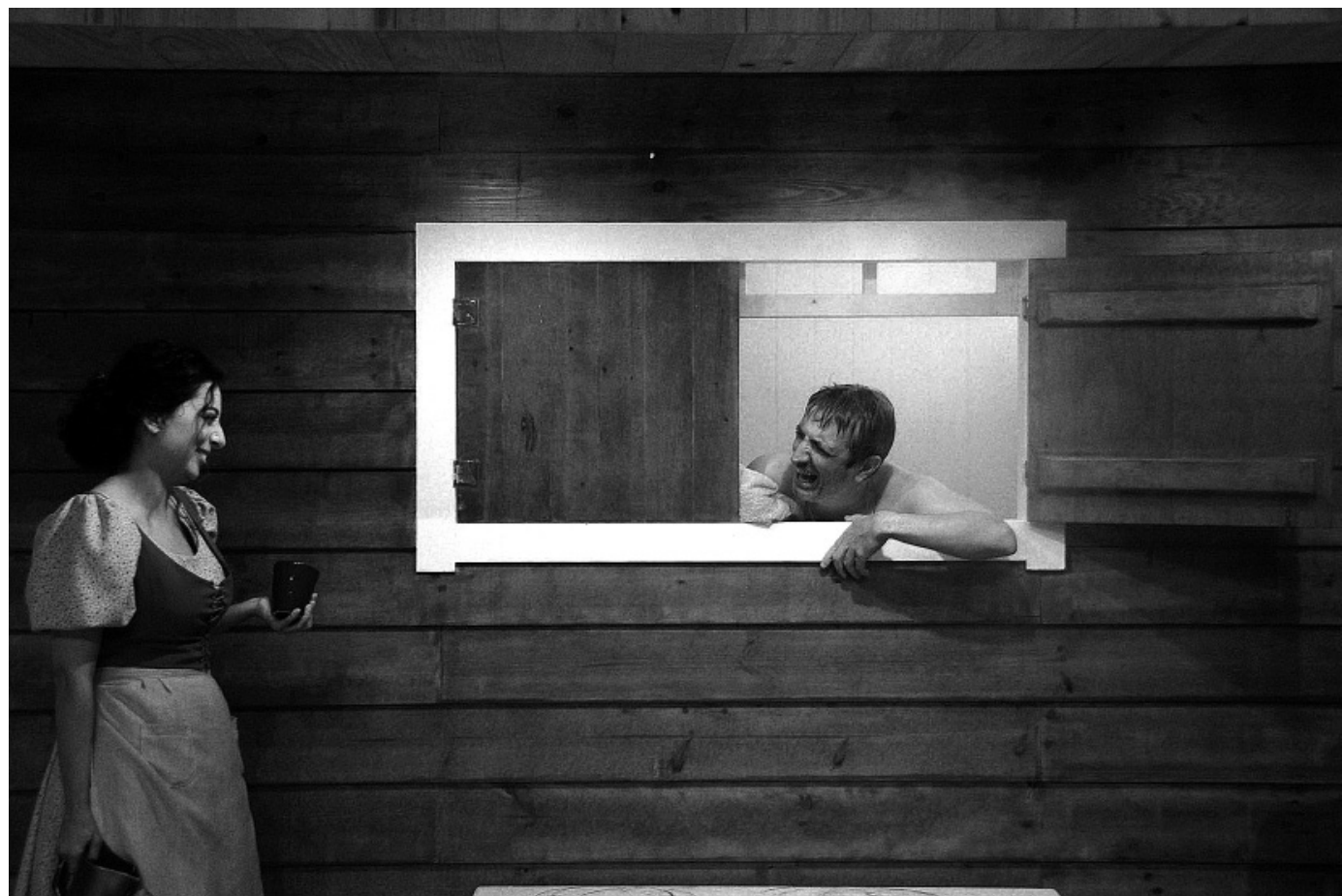

brilhantemente toda a cartilha brechtiana. Nem tão pouco todos os outros artistas e técnicos envolvidos na criação do espectáculo, com substantivo destaque para a excelente música de Shahryar Mazgani e para os figurinos de Bernardo Monteiro.

Mas: e o Miguel Guilherme? 0 actor Miguel Guilherme conseguia ser o pivô da argumentação política. Conseguia ser o elo (mais) visivel da incrivel ginástica do espectáculo em divertir nunca perdendo o ângulo ideológico nem a sua espessura temática. A riquíssima paleta expressiva de Miguel Guilherme - que temos podido ver em acção em vários palcos nacionais e em diferentes registos: na publicidade, no cinema, na televisão, e que fazem de Miguel Guilherme um dos actores mais completos e mais versáteis da cena nacional - era aqui posta ao serviço de um gesto maior. Num espectáculo que durava um pouco mais de duas horas, Miguel Guilherme estava quase sempre em cena e quase sempre apresentando uma personagem ébria, febril e centrifuga, dominando exemplarmente o registo e o tempo cómicos, e aliando a isso uma compreensão precisa da densidade do discurso do espectáculo.

Num texto muito pouco visitado em Portugal, Miguel Guilherme ofereceu-nos uma interpretação verdadeiramente histórica, de qualidade superlativa, de argúcia felina e inteligência maior; ofereceu-nos um
Senhor Puntila composto com brilho e excelência, articulando a alegria do contacto síncrono com o público, num movimento de temperatura popular que visa divertir com um entendimento vasto do gesto e da necessidade do projecto.

0 corpo de Miguel Guilherme parecia saber intuitivamente que, tal como Brecht afirmava, "a causa dos divertimentos é, de entre todas, a que menos necessita de ser advogada" (Brecht 1964: 163). Simultaneamente, a partitura global do actor mostrava claramente que nunca perdeu de vista que "todas as artes contribuem para a maior de todas as artes - a arte de viver" (Ibidem 1964: 215).

É por estas razões que foi da mais elementar justiça atribuir ao actor Miguel Guilherme uma Menção Especial da Crítica.

\section{Referências bibliográficas}

BRECHT, Bertolt (1964), Estudos sobre teatro, coligidos por Siegfried Unseld, tradução Fiama Hasse Pais Brandão, Lisboa, Portugália Editora.

KELLEHER, Joe (2009), Theatre \& Politics, Houndmills, Basingstoke, Hampshire, Palgrave Macmillan.

PAVIS, Patrice (2003), A análise dos espectáculos (1996), trad. Sérgio Sálvia Coelho, S. Paulo, Editora Perspectiva. 